\title{
ARTIKELEN
}

\section{Wetenschap en praktijk in RegelMaat}

\author{
Beoordelingsmaatstaven voor publicaties
}

\section{F.J. van Ommeren}

\section{Inleiding}

$\mathrm{Al}$ een flink aantal jaren is er veel te doen over het wetenschappelijke gehalte van de in de Nederlandse juridische literatuur gepubliceerde bijdragen. Het is niet overdreven te stellen dat hierover al geruime tijd een ware discussie woedt. ${ }^{1}$ In het verlengde hiervan wordt aan de redacties van wetenschappelijke tijdschriften - terecht - gevraagd zowel de procedure als de maatstaven aan de hand waarvan zij artikelen voor hun tijdschrift beoordelen meer uitdrukkelijk voor het voetlicht te brengen. Daar is veel voor te zeggen, niet alleen om principiële, maar ook om praktische redenen. Immers, voor veel auteurs, en zeker voor de minder ervaren auteurs, is het helemaal niet zo duidelijk hoe de redacties van wetenschappelijke tijdschriften te werk gaan. ${ }^{2}$

In de literatuur is wel opgemerkt dat er weinig zicht bestaat op de criteria die de beoordelaars van wetenschappelijke artikelen zouden moeten hanteren. ${ }^{3}$ Inderdaad bestaat daarover in de doctrine weinig overeenstemming, mogelijk mede omdat de meningen nogal uiteenlopen over wat wetenschap voor het vakgebied van het recht eigenlijk betekent. Is recht een wetenschap of een geleerdheid? $\mathrm{Nu}$ is dat in abstracto een nogal moeilijk te beantwoorden vraag. Dat neemt echter niet weg dat de meeste juridische wetenschappelijke tijdschriften wel enige maatstaven kennen, die zij echter niet steeds expliciteren. ${ }^{4}$

Deze bijdrage heeft primair tot oogmerk de werkwijze en de maatstaven aan de hand waarvan de redactie van RegelMaat conceptartikelen beoordeelt uit de doeken te doen. Van de gelegenheid is gebruikgemaakt om ook kort stil te staan bij de

1 Zie vrij recent R.A.J. van Gestel, 'Kwaliteit van juridische publicaties', in: R.H. de Bock, P.J.P.M. van Lochem \& R.A.J. van Gestel, Kwaliteit als keuze (preadviezen NJV), Deventer: Wolters Kluwer 2015, p. 243 e.v.

2 Vgl. W. van Boom, Zeg, wat doen jullie eigenlijk in die tijdschriftredactie? Blog 29 maart 2016, willemvanboom.blog.

3 J. Struiksma, 'De wetenschappelijkheid van het Tijdschrift voor Bouwrecht', TBR 2014/90, p. 485 e.v.

4 Voor het uitschrijven van dit beoordelingskader heb ik gegrasduind op de websites van andere juridische wetenschappelijke tijdschriften, ook om te bezien hoe die zich tot elkaar verhouden. Voor zover ze al tot uitdrukking zijn gebracht, zijn de maatstaven meestal uiterst summier verwoord. Zoals viel te verwachten, stemmen de gevonden eisen voor een belangrijk deel overeen, maar zijn er ook enige substantiële verschillen. 
mogelijke impact van de publicaties in dit tijdschrift. Voor wie is dit alles interessant? Over het algemeen is dit meer direct van belang voor de (potentiële) auteurs dan voor de lezers. Maar ook voor de lezer is deze problematiek niet geheel van relevantie ontbloot. Immers, ook de lezer wil weten uit welke hoek de wind waait, hoe de bijdrage moet worden beschouwd en hoe zwaar eraan kan worden getild. Tegen deze achtergrond kan men de bijdragen beter plaatsen. Wellicht winnen de publicaties van RegelMaat daardoor aan zeggingskracht.

\section{Werkwijze}

Voor de goede orde eerst iets over de werkwijze. De meeste afleveringen van RegelMaat zijn themanummers. In elk themanummer staan zowel wetenschappelijke bijdragen als bijdragen uit de wetgevingspraktijk. Daarnaast is er een drietal rubrieken: 'Het ambacht', 'Objects trouvés' en 'Buitenlands nieuws'. Deze rubrieken worden gevuld door vaste medewerkers van RegelMaat en kunnen hier dus verder buiten beschouwing blijven. Een themanummer sluit niet uit dat daarin ook een enkele bijdrage is opgenomen die niet binnen de reikwijdte van het thema valt. Dit laatste maakt het mogelijk ook spontaan ingezonden bijdragen een plaats te bieden.

RegelMaat ontvangt vrij regelmatig door auteurs uit eigen beweging ingezonden artikelen, zowel uit wetenschappelijke hoek als uit de wetgevingspraktijk. De redactie benadert daarnaast actief auteurs om aan een bepaald themanummer een bijdrage te gaan leveren. Het komt soms voor dat een spontaan ingezonden bijdrage voor de redactie aanleiding is om er enige bijdragen bij te vragen, zodat deze tezamen een themanummer kunnen vormen. Het werken met themanummers staat er aldus niet aan in de weg dat auteurs uit eigen beweging een bijdrage ter publicatie kunnen aanbieden aan RegelMaat.

De bijdragen uit de wetgevingspraktijk worden veelal, maar niet altijd geschreven door ambtenaren van de ministeries. Het zal niet verwonderen dat zij vaak werkzaam zijn bij de verschillende directies Wetgeving en Juridische Zaken, maar noodzakelijk is dat niet. RegelMaat publiceert ook bijdragen afkomstig uit de advocatuur of van medewerkers van toezichthouders of uitvoeringsorganisaties, waarin zij hun praktijkblik op bepaalde aspecten van wetgeving laten schijnen.

Met name voor wetenschappelijke auteurs is het van groot belang vrij precies te weten aan de hand van wat voor soort procedure de bijdrage wordt beoordeeld. $\mathrm{Zij}$ moeten immers in de academische wereld kunnen aantonen dat hun bijdrage een voldoende wetenschappelijk karakter heeft. De redactie beoordeelt de ingezonden bijdragen in veruit de meeste gevallen zelf en wel met alle redacteuren. Zij behoudt zich het recht voor een conceptbijdrage aan één of meer externe deskundigen voor te leggen. In beginsel komen alle bijdragen twee keer in de redactie ter sprake. De eerste keer om te bezien of en in hoeverre het stuk aan de gestelde eisen voldoet en voor plaatsing in aanmerking komt, en de tweede keer om te 
bezien of en in hoeverre de in de eerste ronde gemaakte opmerkingen in acht zijn genomen. ${ }^{5}$

Het is voor wetenschappelijke auteurs mogelijk hun bijdrage blind of dubbelblind te laten beoordelen. Deze auteurs dienen dat uiteraard tijdig aan de redactiesecretaris kenbaar te maken, zodat deze de namen van de auteurs en eventueel ook van de beoordelaars kan anonimiseren. In de praktijk wordt er weinig om gevraagd, maar voor auteurs die daar behoefte aan hebben, is deze faciliteit wel degelijk beschikbaar. In het midden kan hier blijven in hoeverre deze procedure 'peer reviewed' mag heten. ${ }^{6}$

De eindverantwoordelijkheid voor het wel of niet publiceren van een aangeboden bijdrage ligt altijd bij de redactie. Wel is er een Raad van Advies, waardoor de redactie zich graag laat bijstaan voor het maken van meer strategische keuzes, zoals over het soort thema's waaraan RegelMaat in de toekomst aandacht zou kunnen besteden.

\section{Beoordelingskader}

Sinds enige jaren maakt de redactie van RegelMaat gebruik van een beoordelingskader - een beoordelingsformulier - aan de hand waarvan wij ingezonden bijdragen beoordelen. Dit formulier is als bijlage bij deze bijdrage opgenomen. Een dergelijk formulier is een geschikt hulpmiddel om de binnengekomen bijdragen op een objectieve en gelijkwaardige manier te beoordelen en om te voorkomen dat aan de ene bijdrage andere eisen worden gesteld dan aan de andere. Bovendien heeft een dergelijke werkwijze het voordeel dat in het overleg binnen de redactie gemakkelijker en sneller verschillen van inzicht boven tafel komen en de kans wordt verminderd dat belangrijke aspecten over het hoofd worden gezien. Zo'n uniform beoordelingskader heeft dus zowel naar buiten toe - extern - als in de boezem van de redactie - intern - aantrekkelijke kanten. Overigens moeten we de voordelen niet overdrijven: door het vrij hoog abstracte karakter van een dergelijk beoordelingskader is er volop ruimte om in concreto tot verschillende opvattingen over een bijdrage te komen.

\section{Wetenschappelijke bijdragen en praktijkbijdragen}

De wetenschappelijke bijdragen en de bijdragen uit de praktijk worden niet volledig aan de hand van dezelfde maatstaven beoordeeld. RegelMaat heeft enige maatstaven die voor álle te beoordelen bijdragen gelden en voorts enige specifieke maatstaven voor de wetenschappelijke bijdragen en enige andere specifieke maatstaven voor de bijdragen uit de wetgevingspraktijk.

5 In geval van spoed en bij voldoende gebleken kwaliteit wordt wel eens met één ronde volstaan.

6 De opvattingen over wanneer een bepaalde beoordelingsprocedure wetenschappelijk gezien als 'peer reviewed' moet worden aangemerkt, lopen zeer uiteen, zie Van Gestel 2015, p. 269. 
De kern van het wetenschappelijke van een bijdrage is dat zij kennis vermeerdert: het stuk voegt iets nieuws toe aan de stand van de wetenschap. Bovendien moet uit een wetenschappelijk stuk blijken dat voor het verwerven van deze kennis een verantwoorde methode is gehanteerd. Om aan deze eisen te kunnen voldoen is vrijwel steeds, meer of minder expliciet, de structuur van vraag en antwoord vereist. ${ }^{7}$ Met andere woorden: een wetenschappelijke publicatie vereist een heldere onderzoeksvraag met een antwoord en bovendien dient duidelijk te zijn op welke wijze dat antwoord tot stand is gekomen.

Een praktijkbijdrage heeft een andere functie. Een stuk uit de wetgevingspraktijk doet verslag van een bepaalde praktijkervaring. Een bijdrage uit de wetgevingspraktijk is informatief, bijvoorbeeld doordat zij uitleg geeft over nieuwe soorten wetgeving of inzicht biedt in ervaringen met wetgeving of het wetgevingsproces. Een dergelijke publicatie is niet zozeer gericht op kennisvermeerdering, als wel op kennisdeling. Bijdragen uit de wetgevingspraktijk fungeren als het ware meer als doorgeefluik voor bepaalde kennis of informatie uit de praktijk dan dat zij vernieuwend in de zin van oorspronkelijk zijn.

De overgang van kennisvermeerdering naar kennisdeling is overigens enigszins fluïde. De grens tussen wetenschap en wetgevingspraktijk kan dan ook juist in het recht heel dun zijn: het werk van de wetgever kán immers in hoge mate innovatief van aard zijn.

Niet alle bijdragen behoren steeds tot de ene of de andere categorie. Er zijn bijvoorbeeld bijdragen die niet wetenschappelijk van aard zijn, maar die ook niet afkomstig zijn uit de wetgevingspraktijk. Te denken valt aan een van een wetenschapper afkomstige vakpublicatie. In de themanummers van RegelMaat komt dat soort bijdragen betrekkelijk weinig voor, maar voor zover daarvan sprake is, wordt dat expliciet tot uitdrukking gebracht.

\section{De maatstaven}

Teneinde een goed beeld te krijgen van de criteria aan de hand waarvan de redactie de ingezonden bijdragen beoordeelt, worden de maatstaven hier een voor een kort toegelicht. Vanzelfsprekend valt er over deze maatstaven veel meer te zeggen dan in dit bestek mogelijk is. Het gaat er hier louter om de criteria te verduidelijken.

7 Terzijde: een keiharde eis is dat volgens mij niet. Er zijn prachtige wetenschappelijke artikelen geschreven die geen vraag-en-antwoordstructuur kennen. Zie voor een terechte relativering ook J. Smits, Omstreden rechtswetenschap. Over aard, methode en organisatie van de juridische discipline, Den Haag: Boom Juridische uitgevers 2009, p. 161 e.v. 


\section{Onderzoeksvraag (probleem- en doelstelling)}

- Is de bijdrage gebaseerd op een duidelijk geformuleerde en relevante onderzoeksvraag of probleemstelling?

De eerste maatstaf heeft betrekking op de onderzoeksvraag, op de probleem- en doelstelling. Een wetenschappelijk stuk dient een duidelijke onderzoeksvraag te bevatten. Vaak, maar niet altijd, is die te onderscheiden in een probleem- en doelstelling. De doelstelling geeft aan wat met de beantwoording van de probleemstelling beoogd wordt te bereiken. Van belang is ook dat de achtergrond goed duidelijk wordt gemaakt: wat is de aanleiding om te schrijven en waar komen de probleem- en doelstelling vandaan? Wat is de relevantie van het probleem? Is het een theoretisch of praktisch probleem?

Ofschoon juist van wetenschappelijke bijdragen bij uitstek een heldere probleemstelling wordt gevraagd, gaat het te ver om te zeggen dat bijdragen uit de praktijk niet eveneens op een duidelijke en relevante probleemstelling zouden moeten berusten. Ook van een stuk uit de wetgevingspraktijk moet, al dan niet impliciet, duidelijk zijn waarom het is geschreven en wat de lezer eraan heeft om er kennis van te nemen.

\section{Originaliteit en innovatie}

- Verschaft de bijdrage nieuwe inzichten voor het oplossen van vragen of problemen op het terrein van wetgeving?

Niet elke onderzoeksvraag is wetenschappelijk van aard. Om wetenschappelijk te zijn is nodig dat de beantwoording van de onderzoeksvraag leidt tot kennisvermeerdering. In die zin dient een wetenschappelijk stuk innovatief te zijn. Het kan gaan om het stellen van nieuwe vragen, maar dat is niet noodzakelijk. Het kan ook gaan om het geven van nieuwe of andere antwoorden op vragen die al eerder zijn gesteld. Ook kan het gaan om het creëren van een zekere ordening op een nog niet goed ontgonnen (deel)terrein. Juist voor juridisch onderzoek is dit laatste relevant, omdat aan juridische categorieën in het recht de nodige consequenties worden verbonden. Idealiter komt de wetenschappelijke auteur met nieuwe theorievorming op de proppen, maar dat is niet per se nodig om aan het vereiste van originaliteit te voldoen. Enige mate van innovatie is wel vereist.

Ook voor de bijdragen uit de praktijk geldt dat de bijdrage toegevoegde waarde moet hebben. In elk geval dient zij nieuwe inzichten te verschaffen voor het publiek. Niet gezegd is dat deze inzichten voor de eigen organisatie, zoals op het departement waar de praktijkervaring is opgedaan, vernieuwend moeten zijn. Voor een wetenschappelijk tijdschrift als RegelMaat is vooral relevant dat het tijdschrift de eerste is die deze praktijkervaring voor een groter publiek openbaart. 


\section{Structurering en argumentatie}

- Getuigt de bijdrage van voldoende diepgang en geeft zij een helder en systematisch inzicht in de gevolgde - kritische en onafhankelijke - gedachtegang en argumentatie?

Voor wetenschappelijke bijdragen geldt dat op grond van de probleemstelling (en aan de hand van de daarbij gekozen methode, waarover nr. 6) op basis van het gevonden onderzoeksmateriaal een - kritische en onafhankelijke - analyse dient te worden gemaakt. De argumentatie van de bijdrage dient goed te kunnen worden gevolgd en de daarvoor benodigde stappen dienen te kunnen worden geverifieerd. Dit brengt welhaast als vanzelf met zich dat het stuk goed dient te zijn gestructureerd (in die zin een 'logische' opbouw dient te hebben) en grondig en diepgaand van aard dient te zijn. Vanuit wetenschappelijk perspectief is het min of meer vanzelfsprekend dat de bijdrage onafhankelijk behoort te zijn. ${ }^{8}$

Ook voor bijdragen uit de praktijk is het uiteraard van belang dat zij voldoende diepgang hebben en een helder en systematisch inzicht verschaffen in de gevolgde gedachtegang en argumentatie. De eis van verifieerbaarheid kan aan praktijkbijdragen niet steeds worden gesteld. Ofschoon dat wel wenselijk is en zeer op prijs wordt gesteld, is het niet helemaal reëel van een auteur uit de praktijk te verwachten dat deze steeds kritisch tegenover zijn eigen praktijk staat en geheel onafhankelijk daarvan tot zijn oordeelvorming kan komen. Zo hoog wordt de lat ten aanzien van praktijkbijdragen dan ook niet gelegd.

\section{Conclusies en bevindingen}

- Zijn de conclusies en bevindingen voldoende adequaat, duidelijk en gestaafd? Vanzelfsprekend dient de onderzoeksvraag te worden beantwoord en van een onderbouwing te zijn voorzien. Niet uitgesloten is dat het antwoord een voorlopig karakter heeft, geconditioneerd is of vervolgonderzoek vergt, mits dan wel een oplossingsrichting wordt geschetst. De wetenschappelijke conclusie heeft bij voorkeur een beschouwend of beoordelend karakter. Met andere woorden: wat vindt de auteur van wat hij heeft aangetroffen en is voldoende duidelijk op grond waarvan hij die mening is toegedaan? Van belang is dat de bevindingen voldoende voortvloeien uit het gehanteerde onderzoekskader en de daarbij behorende argumentatie.

Ook voor de bijdragen die afkomstig zijn uit de praktijk geldt het vereiste dat de conclusies en bevindingen voldoende adequaat, duidelijk en gestaafd zijn gepresenteerd. Het wordt bovendien zeer op prijs gesteld als de auteur kan reflecteren op wat hij heeft aangetroffen. Noodzakelijk is dat laatste echter niet: het kan zijn dat de auteur vanwege zijn werkkring niet de ruimte heeft een eigen mening te ventileren. Het kan ook zijn dat vanwege het gebrek aan afstand en de te geringe mate van onafhankelijkheid een eigen visie niets zou toevoegen.

8 Het viel mij echter op dat geen enkel door mij geraadpleegd tijdschrift uitdrukkelijk de eis van onafhankelijkheid stelt, terwijl dat toch een wezenskenmerk van wetenschap is! 


\section{Stand van zaken en ontwikkelingen in de wetenschap}

- Biedt de bijdrage een goed overzicht van en inzicht in de recente ontwikkelingen en geeft zij de stand van het wetenschappelijk debat correct weer?

Deze vraag en de daaropvolgende vraag worden uitsluitend gesteld aan de wetenschappelijke bijdragen. Om te kunnen beoordelen of een wetenschappelijk stuk daadwerkelijk iets toevoegt - met andere woorden: tot kennisvermeerdering leidt -, moet het inzicht verschaffen in de stand van zaken en ontwikkelingen waarop het voortbouwt. Het is derhalve de vraag waaraan het stuk een bijdrage beoogt te leveren, zoals wet- en regelgeving, rechtspraak, literatuur of een bepaald maatschappelijk debat. Geeft het artikel een goed inzicht in het daarover gevoerde wetenschappelijke debat?

\section{Methode en bronnengebruik}

- Is het onderzoek verricht op basis van een wetenschappelijk verantwoorde methode en blijkt dit voldoende uit de bijdrage?

Een wetenschappelijk stuk dient duidelijk te zijn over de gevolgde methode. De methode dient voldoende geschikt te zijn om de gestelde onderzoeksvraag adequaat te beantwoorden. Hierbij kan sprake zijn van de klassiek juridische methode (soms ook wel aangeduid als de juridisch-dogmatische methode ${ }^{9}$ ) - die gebaseerd is op de bestudering van de relevante wet- en regelgeving, de rechtspraak en de literatuur over nationaal en Europees recht - al dan niet voorzien van rechtsvergelijking (zowel extern als intern) en interdisciplinair onderzoek (waarbij gebruik wordt gemaakt van sociaalwetenschappelijke, economische, historische, filosofische of andere wetenschappelijke inzichten). Het interdisciplinaire onderzoek is voor RegelMaat des te meer van belang, nu het tijdschrift betrekking heeft op vraagstukken over wetgeving in brede zin. De hoofdstroom van het tijdschrift is weliswaar juridisch, maar er is zeker plaats voor bijdragen met een andere invalshoek. Hoewel uit wetenschappelijk oogpunt een expliciete aanduiding van de methode wenselijk is, is met name bij klassiek juridisch onderzoek niet uitgesloten dat in het licht van de probleemstelling een impliciet aangeduide methode voldoende helder is.

Wetenschappelijke uitlatingen dienen verifieerbaar of in elk geval falsifieerbaar te zijn. Daarom is het gebruik van bronnen van groot belang. Het bronnenapparaat dient adequaat en volledig te zijn. Praktisch betekent dit dat alle gedane uitlatingen onderbouwd moeten zijn door middel van een bronverwijzing; dit ligt slechts

9 Vgl. J.B.M. Vranken, Mr. C. Assers Handleiding tot de beoefening van het Nederlands Burgerlijk Recht. Algemeen deel****. Een synthese, Deventer: Kluwer 2014, nrs. 8. e.v., p. 6 e.v. en M. Snel, Meester(s) over bronnen. Een empirische studie naar kwaliteitseisen, gevaren en onderzoekstechnieken die betrekking hebben op het brongebruik in academisch juridisch-dogmatisch onderzoek (diss. Tilburg), Den Haag: Boom juridisch 2016. 
anders als het om feiten van algemene bekendheid gaat dan wel het een nieuw inzicht of originele opvatting betreft. ${ }^{10}$

\section{Stand van zaken en ontwikkelingen in de praktijk}

- Biedt de bijdrage een goed overzicht van en inzicht in recente ontwikkelingen?

Deze vraag en de daaropvolgende vraag worden uitsluitend gesteld aan de bijdragen uit de wetgevingspraktijk. Van praktijkbijdragen mag worden verwacht dat zij voldoende inzicht verschaffen in wat er in de praktijk is gebeurd, in wat er nieuw is en wat er aan de stand van zaken van het verleden is toegevoegd. Van een praktijkbijdrage wordt evenwel niet geëist dat zij een weergave biedt van het debat in de literatuur.

\section{Beeld voor breder publiek}

- In hoeverre geeft de weergave van de praktijk een afgewogen beeld voor een breder publiek?

Praktijkbijdragen worden meestal geschreven door zeer gespecialiseerde deskundigen. Voor RegelMaat zijn deze deskundigen afkomstig uit de wetgevingspraktijk. De primaire functie van praktijkbijdragen is dat zij een breder publiek informeren. Vereist is dat deze bijdragen een afgewogen beeld van die praktijk schetsen. Van belang is ook dat dit beeld niet dermate specialistisch is verwoord, dat de buitenwacht het niet goed meer kan volgen. Juist uit de vaardigheid om vaktechnische of complexe zaken in betrekkelijk gewone en algemene bewoordingen te kunnen formuleren blijkt dat de auteur echt boven zijn of haar onderwerp staat.

\section{De impact van de publicaties}

Wie wil weten wat de impact van een publicatie is, kan al lang niet meer vooruit met de papieren oplage van het tijdschrift waarin zij staat afgedrukt. En dan laat ik nog maar daar dat te betwijfelen valt of het oplagecijfer ooit een goede graadmeter is geweest. Hoe dan ook, RegelMaat heeft (nog) ruim honderd abonnees met een papieren abonnement. Het overgrote deel van de abonnees is inmiddels overgestapt naar een digitaal abonnement, eventueel aangevuld met een papieren versie. Het vroegere criterium van de betaalde papieren abonnementen wordt dan ook steeds vaker vervangen door het volgen van de digitale toegang.

De uitgever van RegelMaat maakt sinds enige tijd inzichtelijk hoe vaak een artikel online wordt geraadpleegd of gedownload. Er zijn verschillende ingangen. Via de website van Boom juridisch wordt RegelMaat op dit moment meer geraadpleegd

10 Ik meen dat we op deze plaats met deze vuistregel - in wezen een hoofdregel met twee uitzonderingen - goed kunnen volstaan. Dat neemt niet weg dat juist hierover in de literatuur niet ten onrechte meer genuanceerd wordt gedacht. Zie o.a. Asser/Vranken, Algemeen dee ${ }^{* * * *}$ 2014/89 e.v., p. 107 e.v. en Snel 2016 (passim). 
dan via het meer omvattende, maar nog jonge Boomportaal. ${ }^{11}$ Een snelle blik op de website leert dat in de eerste helft van dit jaar RegelMaat ruim 35.000 paginaweergaven had. Wordt er rekening gehouden met het aantal unieke paginaweergaven, dan gaat het nog steeds om meer dan 30.000. Dit is reeds na een halfjaar meer dan een verdubbeling vergeleken met het aantal paginaweergaven over het gehele jaar 2016. Het lijdt dus geen twijfel dat het aantal elektronische bezoeken hard stijgt. RegelMaat is een van de meest geraadpleegde tijdschriften uit het fonds, zeker via het zogeheten Boomportaal.

De impact van het tijdschrift schuilt natuurlijk niet alleen in de digitale vindbaarheid op zichzelf. De juridische wereld is hard op weg naar een kennis- en informatiesysteem dat steeds meer wordt verrijkt met allerlei nieuwe zoek-, citeer- en combineermogelijkheden. ${ }^{12}$ Het is nog even afwachten op welke wijze daarvan in de nabije toekomst gebruik zal worden gemaakt.

\section{Slot}

In de academische wereld valt al jaren te beluisteren dat de werkwijze van het (klassiek) juridische onderzoek te veel een verhulde, vakinterne aangelegenheid is. Ofschoon daarover inmiddels toch het nodige is geschreven, blijft het blijkbaar lastig het vanzelfsprekende onder woorden te brengen. De bedoeling van dit stuk was mede daaraan een bijdrage te leveren. Waarvan akte.

11 Boomportaal maakt de tijdschriften van Boom toegankelijk voor werknemers bij overheidsinstellingen, waaronder de ministeries en de rechterlijke macht.

12 Vgl. W. Soetenhorst, 'Een juridische citatie-index. Het proof of concept is voorhanden', NJB 2017/915, p. 1184 e.v. 


\section{Bijlage}

\section{Beoordelingsformulier RegelMaat}

Vragen te beantwoorden voor alle bijdragen:

I. Is de bijdrage gebaseerd op een duidelijk geformuleerde en relevante onderzoeksvraag of probleemstelling?
In hoge mate
000000
In het geheel niet

2.

Verschaft de bijdrage nieuwe inzichten voor het oplossen van vragen of problemen op het terrein van wetgeving?
In hoge mate
00000
In het geheel niet

3.

Getuigt de bijdrage van voldoende diepgang en geeft zij een helder en systematisch inzicht in de gevolgde - kritische en onafhankelijke gedachtegang en argumentatie?
In hoge mate
00000
In het geheel niet

4.

Zijn de conclusies en bevindingen voldoende adequaat, duidelijk en gestaafd?
In hoge mate
00000
In het geheel niet

Vragen te beantwoorden voor wetenschappelijke bijdragen:

5.

Biedt de bijdrage een goed overzicht van en inzicht in de recente ontwikkelingen en geeft zij de stand van het wetenschappelijk debat correct weer?
In hoge mate
00000
In het geheel niet

6. Is het onderzoek verricht op basis van een wetenschappelijk verantwoorde methode en blijkt dit voldoende uit de bijdrage?
In hoge mate
000000
In het geheel niet

Vragen te beantwoorden voor bijdragen uit de wetgevingspraktijk:

7.

8.

Biedt de bijdrage een goed overzicht van en inzicht in recente ontwikkelingen?

In hoge mate

00000

In het geheel niet

In hoeverre geeft de weergave van de praktijk een afgewogen beeld voor een breder publiek?

In hoge mate

00000
In het geheel niet 